\title{
The Housing Cost Disease *
}

\author{
Nicola Borri Pietro Reichlin \\ LUISS LUISS \& CEPR
}

This version: October 28, 2017

\begin{abstract}
Using a simple two-sector life cycle economy with housing services and bequests, we show that a rising labor efficiency in the general economy relative to the construction sector can go a long way toward explaining a significant fraction of the rising trends in wealth-to-income ratios, housing wealth, and wealth inequality, that have been documented in most advanced countries at least since the '70s. This mechanism (which we label housing cost disease) has adverse effects on social welfare when the Planner puts sufficient weight on the less wealthy households.
\end{abstract}

KeYwords: Housing Wealth, Cost Disease, Overlapping Generations, Wealth Inequality.

JEL CoDES: D91, O11, H2, G1.

*Borri: Department of Economics and Finance, LUISS University, Viale Romania 32, 00197 Rome, Italy; nborri@luiss.it; Tel: +39 06 85225959; http://docenti.luiss.it/borri. Reichlin: Department of Economics and Finance, LUISS University, Viale Romania 32, 00197 Rome, Italy; preichlin@luiss.it; Tel: +39 06 85225554; http://docenti.luiss.it/reichlin. We thank seminar and conferences participants at Barcelona GSE, University of Tokyo, Bank of Japan, Kyoto University, LSE. Support of a grant from MURST, PRIN 2010, is gratefully acknowledged. We thank Alberto Martin, Ingvar Strid, Gregory Thwaites and Thomas Steger for helpful comments. A separate online appendix available on our web sites contains additional results and robustness checks and details on the data. 


\section{Introduction}

Wealth-to-income ratios have been increasing in most advanced economies at least since the 1970s, and housing wealth, which accounts for about $35 \%$ of the total, has been the main driver in many countries. Because wealth is more unevenly distributed than income, a concern for a widening inequality gap is emerging in academic and non-academic circles. In fact, in advanced countries, wealth inequality, while declining in the period 1950 to 1970, has been increasing at least since 1980 .

A growing literature suggests that to understand the existing trends in wealth inequality, wealth ratios and income shares, it is crucial to analyze the dynamics of housing, since much of the long-term dynamics of the capital-income ratio, as well as the net capital share of income, is accounted for by housing wealth and, in particular, by rising housing prices (for example, Bonnet et al. (2014), Piketty and Zucman (2014), Rognlie (2014) and Summers (2014)). Following this literature, we provide an explanation of these long run trends based on a sort of Baumol's cost disease. In particular, we build a frictionless two-sector life-cycle model with bequests able to replicate some of the stylized facts concerning the dynamics of total wealth, housing wealth, and wealth inequality, as a consequence of an improvement in the efficiency of labor in the rest of the economy relative to the construction sector.

In the seminal work by Baumol (1967), a market economy has two sectors pro-

ducing two goods using labor as the only input and enjoying different patterns of technological progress. Under perfect labor mobility and wage equalization, a rising labor productivity in the dynamic sector, relative to the stagnant sector, generates a higher production cost and, then, a rising relative output price in the stagnant sector. If the demand of the stagnant sector output is sufficiently inelastic, labor will move to this sector and aggregate output growth may decline. We extend Baumol's analysis to a life-cycle model with bequests (generated by parental altruism). The two sectors are called construction and manufacturing, where the former should be inter- 
preted as production of buildings and constructions and the latter as capturing the non-construction sectors of the economy. Technology employs capital and land, as well as labor, and construction plays the role of the stagnant sector, while manufacturing experiences labor-augmenting technological progress. Assuming an altruistic bequest motive, we define the conditions for a rise in the efficiency of labor in manufacturing to generate a housing price appreciation, a rise in the wealth-to-income ratio (mostly driven by a higher housing appreciation and a weak dynamic in average labor productivity) and in the size of bequests (i.e., a rising wealth inequality). We refer to this set of results as the housing cost disease. Data for the 8 largest advanced economies over the period 1970-2010 confirm the existence of a positive and large correlation between a labor-augmenting productivity residual in the rest of the economy, relative to the construction sector, and the total and housing wealth-to-income ratios. A multi-sector approach is important to study the evolution of the wealth composition in advanced economies (vs. economies in the early stage of the development process) since housing replaced land in households' assets and because factor price equalization across sectors generates interesting linkages between the dynamics of productivity and asset prices.

We solve the model analytically, at the steady state and under the assumptions of constant productivity growth rate and Cobb-Douglas production function in the residential construction sector, and show that the housing cost disease is most likely when manufacturing is more capital intensive than construction, housing demand is sufficiently inelastic with respect to its own price and the land share of income is not too large. The housing demand elasticity and the elasticity of substitution between factors play an important role. In particular, with unitary elasticity of substitution between capital and labor in construction, and between goods (consumption and housing services), in a CES representation of preferences, a rising relative productivity in manufacturing is allocation neutral, in the sense that total and housing wealth-to-income ratios, as well as bequests, remain unchanged. When, instead, housing demand is suf- 
ficiently inelastic, the housing cost disease holds and bequests, and thus inequality, increase with relative productivity in manufacturing. The robustness of these results is studied numerically for a CES specification of preferences and technology. We show that, for a $75 \%$ increase in the (exogenous) relative labor-augmenting efficiency in manufacturing (a value that we consider a good estimation of the actual average improvements between 1970 and 2010 for advanced economies), total wealth-to-income increases by about 7.5 percent and housing wealth by approximately 27 percent. These patterns are driven by a strong increase in the housing price (about 60 percent). Since the interest rate is greater than the population growth rate at equilibrium, steady state net bequests (i.e., the difference between the present value of bequests received from the previous generation and those left to the next one) are a positive component of the rich households' present value of income. Then, assuming that housing is a normal good, bequests and housing wealth are correlated, and this dependence is stronger the higher the equilibrium level of the interest rate.

We are not the first to highlight the importance of disaggregated productivity improvements, and changes in the allocation of inputs across sectors, to explain movements in housing prices and wealth. Some notable examples are Davis and Heathcote (2005), Kahn (2008), Iacoviello and Neri (2010), Li and Zeng (2010), Moro and Nuno (2012), and, more recently, Favilukis et al. (2015) and Grossmann and Steger (2016). In particular, Moro and Nuno provide some evidence that a fall in the relative TFP in the construction sector may be responsible for a surge in housing prices, and Grossmann and Steger highlight the scarcity of land as a contributing factor for the increase in wealth-to-income ratios. Li and Zeng (2010) develop a two-sector neoclassical growth model with housing and show that sectoral differences in productivities could explain the secular growth of housing prices. They show that there exists a negative relation, off the balanced growth path, between house prices and real interest rates as long as the housing sector is more labor intensive. Most of the other contributions focus 
on business cycle analysis and credit frictions. Our life-cycle model incorporates land and bequests, which provide additional channels to explain changes in housing prices, wealth composition, inequality and their welfare implications.

Our theory complements, rather than replaces, alternative explanations of these stylized facts based on financial constraints (for example, Favilukis et al. (2015) and Iacoviello (2005)), regulation and the supply of housing and land (for example, Hsieh and Moretti (2015) and Knoll et al. (2017)), precautionary saving (for example, Gourinchas and Parker (2002) and Castaneda et al. (2003)), as well as the saving induced growth mechanism advocated by Piketty and Zucman (2014) who attribute the rising wealth-to-income ratios to the falling income growth rates and the long-run stability of the saving rate ${ }^{1}$. Piketty and Saez (2014) claim that these trends are responsible for the rising income and wealth inequality. Bonnet et al. (2014), Rognlie (2014) and Weil (2015) argue that the existing trends in wealth-to-income ratios and income shares are strongly determined by the dynamic of housing wealth and capital gains. Other contributions explain the observed stylized facts with a combination of alternative assumptions, such as heterogeneous bequest motives, rate of returns shocks and incomplete markets (as in Krusell and Smith (1998), Hendricks (2007), Benhabib et al. (2011), Benhabib et al. (2015)), or endogenous rates of return due to entrepreneurship or human capital (as in Galor and Zeira (1993), Quadrini (2000), Cagetti and De Nardi (2006) and many others). Our model borrows some of the ingredients employed in this literature, within a drastically simplified framework, to explain the rising wealth inequality that goes along with a change in the sectoral composition of GDP. In particular, as in Favilukis et al. (2015), we focus on the role of bequests in generating wealth inequality by assuming that altruistic finitely-lived households have fixed heterogeneous discount rates and that parents cannot force gifts on their children (one-

\footnotetext{
${ }^{1}$ See, in particular, the detailed survey by De Nardi and Fang (2015) and Leung (2004) for a review of the literature.
} 
sided altruism $)^{2}$. This heterogeneity generates a partition of the set of households at steady states into a subset of rich individuals receiving bequests from their parents and a subset of poor individuals receiving (and giving) no bequests. Although the assumption of heterogeneous bequest motives across individuals as a driver of wealth inequality is not new and it has been widely exploited in the existing literature, we supplement this theory by suggesting that the Baumol cost disease may amplify bequests-induced inequality through relative productivity improvements. In particular, our model shows that, when housing demand is sufficiently inelastic with respect to its own price, private wealth, housing prices and bequests are complementary.

Piketty (2014) advocates the institution of a wealth tax on the assumption that the increase in wealth-to-income is not desirable because of the implications in terms of unequal distribution of wealth across households. However, if this phenomenon is mostly a consequence of rising housing prices, then policies targeting specifically the housing sector are probably more appropriate, as noted for example by Auerbach and Hasset $(2015)^{3}$. We leave for future research the evaluation of such policies, and use, instead, the model to see if a change in the composition of wealth toward housing, following a rise of efficiency in manufacturing, is welfare improving. Since households are heterogeneous with respect to private wealth composition, the answer is ambiguous. In particular, in the case of a housing cost disease, a housing appreciation due to productivity improvements has two opposite effects on individuals' welfare: it raises bequests and old individuals' housing wealth, but is also makes housing less affordable. The latter (negative) effect is the only one affecting the poor young households' welfare.

The remainder of the paper is organized as follows. Section 2 introduces the model, the conditions for a housing cost disease to occur, and presents our analytical results.

\footnotetext{
${ }^{2}$ The role of bequests in generating wealth inequality can be hardly ignored. For the US, Gale and Scholz (1994) find that intergenerational transfers account for at least 50-60\% of total wealth accumulation.

${ }^{3}$ Note that housing taxation is, in any case, very controversial, since housing is a consumption good, as well as an asset, and home ownership is much more evenly distributed across individuals than stocks and other financial assets.
} 
Section 5 provides a quantitative analysis of the model under a reasonable calibration. Section 6 presents the empirical evidence supporting our conjecture. Section 7 discusses the welfare implications. Section 8 concludes.

\section{The Model}

In this section we present a simple life-cycle model with bequests, two sectors (construction and manufacturing), two assets (business capital and housing), and exogenous technical progress. The manufacturing sector stands to represent all the nonconstruction sectors of the economy. Both sectors use labor and capital, and land is used in construction only. The model is used in sections 4 and 5 to show analytically and numerically that, when housing demand is sufficiently inelastic and the construction sector less capital intensive than manufacturing, an increase in labor efficiency in manufacturing generates a sizable increase in the steady state values of total and housing wealth-to-income ratios, bequests (i.e., wealth inequality) and housing prices.

There are two sectors, construction $(h)$ and manufacturing $(m)$. Firms in both sectors are price-takers and labor and capital are fully mobile across the two sectors. The production functions are

$$
Y_{t}^{h}=F^{h}\left(K_{t}^{h}, A_{t}^{h} L_{t}^{h}, Z_{t}\right), \quad Y_{t}^{m}=F^{m}\left(K_{t}^{m}, A_{t}^{m} L_{t}^{m}\right)
$$

where $K^{j}$ and $L^{j}$ are the amounts of capital and labor employed in the two sectors, $A^{j}$ is a labor-augmenting technological level and $Z_{t}$ represents the flow of additional land available for residential development. For analytical convenience, we assume that $F^{h}$ and $F^{m}$ are strictly concave, they exhibit constant returns to scale, with $F^{m}$ satisfying standard Inada type conditions, and $F^{h}$ belongs to the class of CES productions functions with elasticity of substitution between inputs defined by $\sigma^{h}$.

As in Davis and Heathcote (2005) and Favilukis et al. (2015), $Z$ is a combination 
of land and government permits. Note that we are implicitly assuming that past flows of new housing do not reduce the land stock available for the current production of housing. We let the flow of additional land permits for residential development, $Z$, be time-dependent because the government, or some other public authority, may decide to change it to enact specific policies or respond to demographic variables. To simplify the exposition, we assume that the proceeds from selling land permits are used by the government to finance wasteful government spending. Our definition of housing production is not limited to new buildings on previously unused land, but includes rebuilding, renovation and construction of new floors of existing houses.

It is convenient to normalize variables with respect to the level of labor efficiency. In particular, let $k^{j}=K^{j} / A^{j} L^{j}$ be the sector-specific capital intensities, $z=Z / A^{h} L^{h}$ the available land per unit of labor efficiency in construction and $y^{j}$ the sector-specific labor productivities in efficiency units. By constant returns to scale, the intensive-form production functions are

$$
y^{h}=F^{h}\left(k^{h}, 1, z\right) \equiv f^{h}\left(k^{h}, z\right) \quad y^{m}=F^{m}\left(k^{m}, 1\right) \equiv f^{m}\left(k^{m}\right) .
$$

Let $a=A^{m} / A^{h}$ be the labor-augmenting efficiency in manufacturing relative to construction (henceforth relative productivity); $q^{h}$ the price of a unit of new housing; $r$ the real interest rate; $w=W / A^{m}$ the wage rate per units of efficiency in the manufacturing sector; $R^{z}$ the real rental rate of land (imposed by the regulator or the government agency); and denote with $f_{k}^{h}$ and $f_{z}^{h}$ the partial derivatives of $f^{h}\left(k^{h}, z\right)$ with respect to $k^{h}$ and $z$, respectively. Then, profit maximization at any interior solution implies

$$
\begin{aligned}
1+r & =f_{k}^{m}=q^{h} f_{k}^{h}, \\
w & =f^{m}-k^{m} f_{k}^{m}=\left(q^{h} / a\right)\left[f^{h}-k^{h} f_{k}^{h}-z f_{z}^{h}\right], \\
R^{z} & =q^{h} f_{z}^{h} .
\end{aligned}
$$


By the properties of the production functions, the above equations provide a well defined map from $(r, a)$ into $\left(w, k^{h}, k^{m}\right)$ for all $a>0$ and $r$ in a suitable interval. Importantly, the CES representation for $F^{h}$ implies that the profit maximizing values of the capital-labor ratios under factor price equalization are independent of the amount of land, $Z$. In particular, by the stated assumptions, it is readily verified that, for any given strictly positive $(r, a)$, with $r \in \mathcal{A}=[\underline{r}, \bar{r}]$, there is a unique solution, $\left(w(r), k^{h}(r, a), k^{m}(r)\right)$ (independent of $\left.z\right)$, to equations (2), (3), as a differentiable function of $(r, a)$, such that $w, k^{h}$ and $k^{m}$ are all decreasing in $r$. Further more, the elasticities of $k^{h}$ and $q^{h}$ with respect to a (for given land to labor ratio, $z$ ) are given by

$$
\hat{k}_{a}^{h}=\frac{\partial k^{h} / k^{h}}{\partial a / a}=\sigma^{h}, \quad \hat{q}_{a}^{h}=1-\mathcal{S}_{k}^{h},
$$

where, as mentioned above, $\sigma^{h}$ represents the elasticity of substitution between inputs in the CES production function and $\mathcal{S}_{k}^{h}=f_{k}^{h} k^{h} / f^{h}$ is the capital share in the construction sector.

A set $L_{t}$ of households, growing at a rate $n \geq 0$, is born every period $t$. Households live for two periods, supply labor time inelastically in young age only, and have identical time-invariant preferences for manufacturing consumption and housing services, the latter being measured by the housing stock. Households are characterized by some degree of altruism with respect to their offsprings defined by an individual specific discount rate of the next generation's utility. In particular, households born at time $t$ belong to different types, indexed by $i$, with $i$ in a finite set $\mathcal{I}$, and each type $i$ composed of a mass $m_{i}$ of individuals (i.e., a collection of positive numbers, $\left(m_{i}\right)_{i \in \mathcal{I}}$, such that $\left.\sum_{i \in \mathcal{I}} m_{i}=1\right)$, with life-time utility defined by:

$$
V^{t, i}=u\left(C_{t}^{y, i}, C_{t+1}^{o, i}, H_{t+1}^{i}\right)+\theta_{i}(1+n) V^{t+1, i}
$$

for all $t \geq 0$, where $\left(C_{t}^{y, i}, C_{t+1}^{o, i}\right)$ are age-contingent consumptions, $H_{t+1}^{i}$ is the housing 
stock acquired by the household in young age and $u($.$) is a standard increasing, concave$ function to be specified in a later section and the (inter-generational) discount factors satisfy $\theta_{i}(1+n)<1$ for all $i \in \mathcal{I}$. The upper bound on the discount rates, $\theta_{i}$, insures convergence of each dynasty's long-run utility function.

We assume perfect financial markets allowing for unlimited lending and borrowing. Any household born at time $t$ acquires residential property when young, enjoys the housing services generated by it, resells the property when old and leaves some bequests to the offsprings. Then, the budget constraints in their two periods of life are

$$
\begin{aligned}
C_{t}^{y, i}+q_{t} H_{t+1}^{i}+D_{t+1}^{i} /\left(1+r_{t+1}\right) & =W_{t}+B_{t}^{i}, \\
C_{t+1}^{o, i}+B_{t+1}^{i} & =D_{t+1}^{i}+q_{t+1}(1-\delta) H_{t+1}^{i},
\end{aligned}
$$

where $D^{i}$ denotes units of a one period financial asset, $B^{i}$ denotes inter vivos bequests, $W$ is the real wage and $\delta \in(0,1)$ is the housing depreciation rate. The above reduce to a single inter-temporal budget constraint

$$
C_{t}^{y, i}+\frac{C_{t+1}^{o, i}}{1+r_{t+1}}+\pi_{t} H_{t+1}^{i}+\frac{(1+n) B_{t+1}^{i}}{1+r_{t+1}}=W_{t}+B_{t}^{i}
$$

where

$$
\pi_{t}=q_{t}^{h}-(1-\delta) q_{t+1}^{h} /\left(1+r_{t+1}\right)
$$

is the user cost of housing. Denoting with $u_{j, t}^{i}$ the partial derivative of $u\left(C_{t}^{y, i}, C_{t+1}^{o, i}, H_{t+1}^{i}\right)$ with respect to the $j$-th argument, standard Euler equations reduce to

$$
u_{1, t}^{i}=\left(1+r_{t+1}\right) u_{2, t}^{i}, \quad u_{1, t}^{i} \pi_{t}=u_{3, t}^{i} .
$$

Since parental altruism is one-sided, we rule out forced gifts from children to parents, and impose the non-negativity constraint $B_{t+1}^{i} \geq 0$. Then, by the the budget 
constraints (8), the optimal allocation of bequests is defined by

$$
u_{2, t}^{i} \geq \theta_{i} u_{1, t+1}^{i}
$$

together with the complementary slackness condition

$$
B_{t+1}^{i}\left(u_{2, t}^{i}-\theta_{i} u_{1, t+1}^{i}\right)=0
$$

From the above budget constraints and first order conditions we derive the time- $t$ households' saving, $S_{t}^{i}$, demand for housing, $H_{t+1}^{i}$, and supply of bequests, $B_{t+1}^{i}$.

Letting $K, L$ and $H$ be the total stocks of business capital, labor and housing, a first set of equilibrium conditions imply

$$
\begin{aligned}
L_{t} & =L_{t}^{h}+L_{t}^{m}, \\
K_{t} & =K_{t}^{h}+K_{t}^{m}, \\
H_{t+1} & =Y_{t}^{h}+(1-\delta) H_{t} .
\end{aligned}
$$

From now on we define with $\lambda_{t}=L_{t}^{h} / L_{t}$ the share of labor in the housing sector and express all equilibrium restrictions and the relevant variables in units of labor efficiency (relative to the manufacturing sector). In particular, letting

$$
k_{t}=K_{t} / A_{t}^{m} L_{t}, \quad h_{t}=H_{t} / A_{t}^{m} L_{t}, \quad 1+g_{t+1}^{m}=A_{t+1}^{m} / A_{t}^{m},
$$

we can replace the full employment conditions (12), (13) and (14) with

$$
\begin{aligned}
k_{t} & =\lambda_{t} k_{t}^{h} / a_{t}+\left(1-\lambda_{t}\right) k_{t}^{m}, \\
(1+n)\left(1+g_{t+1}^{m}\right) h_{t+1} & =\lambda_{t} y_{t}^{h} / a_{t}+(1-\delta) h_{t}
\end{aligned}
$$


and $\lambda_{t} \in[0,1]$. To close the model we define the aggregate saving and housing demand per unit of efficiency

$$
\begin{aligned}
s_{t} & \equiv \sum_{i} m_{i} S^{i} / A_{t}^{m}, \\
h_{t+1}^{d} & \equiv \sum_{i} m_{i} H_{t+1}^{i} L_{t} / A_{t+1}^{m} L_{t+1},
\end{aligned}
$$

and impose market clearing in the the housing and capital markets, i.e.,

$$
\begin{aligned}
h_{t+1} & =h_{t+1}^{d}, \\
(1+n)\left(1+g_{t+1}^{m}\right)\left(k_{t+1}+q_{t}^{h} h_{t+1}\right) & =s_{t} .
\end{aligned}
$$

By the properties of the production functions, profit maximization and factor price equalization at an interior solution, i.e., equations (2) and (3), we recall that

$$
k_{t}^{m}=k^{m}\left(r_{t}\right), \quad k_{t}^{h}=k^{h}\left(r_{t}, a_{t}\right), \quad w_{t}=w\left(r_{t}\right),
$$

and

$$
q_{t}^{h}=\left(1+r_{t}\right) / f^{h}\left(k_{t}^{h}, z_{t}\right) \equiv q^{h}\left(r_{t}, a_{t}, z_{t}\right)
$$

Recall that the functions in (21) and (22) are positive and continuous and guarantee an interior allocation of factors across sectors for $r$ in $\mathcal{A}=[\underline{r}, \bar{r})$ and all $a>0$. Then, an interior competitive equilibrium is a positive sequence,

$$
\left\{k_{t}, k_{t}^{h}, k_{t}^{m}, \lambda_{t}, h_{t}, b_{t}, r_{t+1}, w_{t}, q_{t}^{h}\right\}_{t=0}^{\infty},
$$

with $r_{t+1} \in \mathcal{A}$ and $\pi_{t}=q_{t}^{h}-(1-\delta) q_{t+1}^{h} /\left(1+r_{t+1}\right)>0$ for all $t \geq 0$, satisfying the households' optimality conditions (8), (9), (10), (11), the market clearing conditions (15)-(20), the factor price equalization conditions (21), for all $t \geq 0$, for a given sequence of relative productivities, $\left\{a_{t}\right\}_{t=0}^{\infty}$, flows of housing permits, $\left\{z_{t}\right\}_{t=0}^{\infty}$ and some initial 
conditions, $\left(k_{0}, h_{0}, r_{0}\right)>0$. Given the assumption that the proceeds from selling land permits are used for wasteful government spending, we can neglect the government balanced budget condition since it has no impact on equilibrium variables.

\section{Steady States with Two Types}

From now on we concentrate on a steady state equilibrium where all relevant variables are time invariant in units of labor efficiency (in manufacturing) and the economy grows at a constant growth rate. Evidently, this implies that labor efficiency grows at the same rate in the two sectors, i.e.,

$$
A_{t+1}^{m} / A_{t}^{m}=A_{t+1}^{h} / A_{t}^{h} \equiv 1+g,
$$

otherwise the relative productivity parameter, $a_{t}$, would be growing (or falling) at a constant rate and this would in turn generate ever increasing (or decreasing) relative prices. This assumption, of course, does not imply that the two sectors must have the same level of labor efficiency, and we will be studying the effects of a rise in the relative productivity, $a$, across steady states as well as in a transition between steady states. Remember that the flow of land permits, $Z_{t}$, is set according to some rule determined by a public authority. It is reasonable and consistent with the notion of a steady state equilibrium to impose that this rule follows the demographic and technological evolution of the economy in such a way as to impose a constant cost (represented by $R^{z}$ in equation (4)) on the firms operating in the housing sector. Then, we assume that $z$ is time invariant. However, it should be kept in mind that this is only a convenient assumption. If $Z_{t}$ grew less than the labor efficiency in the construction sector, land would become relatively scarcer over time, and this would amplify the impact of a rising $a$ on housing prices. Hence, our assumption shuts down an additional mechanism feeding the sort of cost disease that we are looking for in this paper. 
For simplicity, we will also make two simplifying assumptions. First, the instantaneous utility function, $u($.$) , belongs to the CES class with elasticity of substitution$ between goods denoted by $\gamma$. In particular,

$$
u\left(C^{y, i}, C^{o, i}, H^{i}\right)= \begin{cases}{\left[\chi^{y}\left(C^{y, i}\right)^{\frac{\gamma-1}{\gamma}}+\chi^{o}\left(C^{o, i}\right)^{\frac{\gamma-1}{\gamma}}+\chi^{h}\left(H^{i}\right)^{\frac{\gamma-1}{\gamma}}\right]^{\frac{\gamma}{\gamma-1}}} & \text { if } \gamma \neq 1 \\ \left(C^{y, i}\right)^{y}\left(C^{o, i}\right)^{o}\left(H^{i}\right)^{\chi^{h}} & \text { otherwise }\end{cases}
$$

where $\chi^{j}>0$ for $j=y, o, h$ and $\sum_{j=y, o, h} \chi^{j}=1$. Importantly, the CES hypothesis guarantees normality, unitary elasticity of consumption and housing demand with respect to income, and the "law of demand" (demand for housing decreasing in its own price). The second assumption is that there are two types of households only. In particular, letting $\mathcal{I}=\{p, r\}$ and $\theta_{r}>\theta_{p}$, we say that household type $r$ is rich and household type $p$ is poor, although we could as well say that the former is more altruistic than the latter with respect to their own children.

Under this specification, and by the first order conditions (9)-(11), it is clear that we may have two types of steady states. In the first, $r \leq\left(1-\theta_{r}\right) / \theta_{r}$ and no individual leaves any bequests, so that the resulting equilibrium is equivalent to the one that would take place in a canonical overlapping generations economy. In the second, the rich individuals leave positive bequests, whereas the poor leave zero bequests at any time. In particular, at a PBSS we have

$$
r=\left(1-\theta_{r}\right) / \theta_{r} \equiv r^{*}<\left(1-\theta_{p}\right) / \theta_{p}
$$

We refer to the first type of equilibrium as a zero bequests steady state (ZBSS) and to the second type as a positive bequests steady state (PBSS). In what follows, we focus exclusively on the latter mostly because it allows for a sharp characterization of intragenerational inequality. It is understood that a PBSS is assumed to be interior, i.e., 
to imply that both sectors are active. In particular, we impose that

$$
\lim _{k^{m} \rightarrow 0} f_{k}^{m}>\min _{i \in \mathcal{I}} 1 / \theta_{i}>\lim _{k^{m} \rightarrow \infty} f_{k}^{m}
$$

The above implies that a PBSS exists and it is such that the wage rate per unit of efficiency is uniquely fixed at $w\left(r^{*}\right)$, whereas $w \geq w\left(r^{*}\right)$ at a steady state with zero bequests. Recalling that any interior allocation provides $k^{m}=k^{m}(r), k^{h}=$ $k^{h}(r, a), y^{h}=y^{h}(r, a, z), q^{h}(r, a, z)$ the allocation of the capital-labor ratios is uniquely determined by $\left(r^{*}, a\right)$ for given $z$. Hence, there are five remaining equilibrium variables to be determined by the steady state equilibrium conditions characterizing a PBSS: the average capital stock, $k$, the share of labor in construction, $\lambda$, the housing stock, $h$, and the steady state bequest of the rich household, $b$, all of them uniquely determined by $\left(r^{*}, a\right)$ and by the market clearing conditions (15)-(20) at steady state.

Now denote with lower case letters the variables in units of labor efficiency at steady state, so that, for $j=y, o$,

$$
c^{j, i}=C_{t}^{j, i} / A_{t}^{m}, \quad s^{i}=S_{t}^{i} / A_{t}^{m}, \quad b^{i}=B_{t}^{i} / A_{t}^{m}, \quad h^{i}=H_{t+1}^{i} / A_{t+1}^{m} .
$$

By the CES utility specification, all variables exhibit a unitary income elasticity. Then, denoting with $I_{t}^{i}$ the household's present value of income in $t$, and setting

$$
(1+n)(1+g)=1+\zeta
$$

we derive

$$
c^{y, i}=\phi^{y}(\pi, r) I_{t}^{i} / A_{t}^{m}, \quad \frac{c^{o, i}}{1+r}=\phi^{o}(\pi, r) I_{t}^{i} / A_{t}^{m}, \quad \pi h^{i}(1+g)=\phi^{h}(\pi, r) I_{t}^{i} / A_{t}^{m},
$$


where, at steady state,

$$
I_{t}^{i} / A_{t}^{m}=w+\left(\frac{r-\zeta}{1+r}\right) b^{i}
$$

and $\phi^{j}(\pi, r) \in(0,1)$ (for $\left.j=y, o, h\right)$ are the expenditure shares. Importantly, for $j=y, o, h, \phi^{j}(\pi, r)$ are all continuous functions and such that

$$
\partial \phi^{y}(\pi) / \partial \pi \leq 0, \quad \partial \phi^{o}(\pi) / \partial \pi \leq 0, \quad \partial \phi^{y}(\pi) / \partial \pi \geq 0
$$

if and only if $\gamma<1$, and $\partial \phi^{j}(\pi) / \partial \pi=0$ for $j=y, o, h$ for $\gamma=1$. Furthermore, households' savings per unit of labor efficiency is

$$
s^{i}=\left(1-\phi^{y}(\pi, r)\right) w+\left(\frac{1+\left(1-\phi^{y}(\pi, r)\right) r+\phi^{y}(\pi, r) \zeta}{1+r}\right) .
$$

Observe that, by the normality of housing and consumption, the households' housing demand and saving are both increasing in bequests under the condition $r>\zeta \geq 0$. Hence, higher bequests generate more housing demand and more saving for the rich individual relative to the poor at the PBSS. More specifically, the impact of a rising bequest on saving is greater than the impact on the money spent on housing ${ }^{4}$, i.e.,

$$
\partial s^{i} / \partial b^{i}>q^{h} \partial h^{i} / \partial b^{i}>0 .
$$

These properties are exploited in the next section to show that a rising relative productivity may go along with a rising housing wealth and rising bequests.

By aggregating across households at steady state (cf. equations (17)-(20)), we get the following expressions for the aggregate steady state levels of housing demand and

\footnotetext{
${ }^{4}$ Notice that these inequalities are not specific of the CES utility representations, but rather hold also in a more general setting under the conditions of normality and $r>\zeta \geq 0$.
} 
savings in units of labor efficiency

$$
\begin{aligned}
h^{d} & =\left(\frac{\phi^{h}(\pi, r)}{(1+\zeta) \pi}\right)\left(w+\left(\frac{r-\zeta}{1+r}\right) b\right), \\
s & =\left(1-\phi^{y}(\pi, r)\right) w+\left(\frac{1+\left(1-\phi^{y}(\pi, r)\right) r+\phi^{y}(\pi, r) \zeta}{1+r}\right) b,
\end{aligned}
$$

and the set of equilibrium conditions (15)-(20) at steady state are

$$
\begin{aligned}
k & =\lambda k^{h}(r, a) / a+(1-\lambda) k^{m}(r) \\
(\delta+\zeta) h & =\lambda y^{h}(r, a) / a \\
h & =h^{d} \\
(1+\zeta)(k+q h) & =s .
\end{aligned}
$$

\section{Some Analytical Results}

We can now explore under what conditions our model replicates some of the features of the two-sector economy studied by Baumol (1967), with construction of housing playing the role of the stagnant sector and manufacturing the role of the dynamic sector. We recall that the Baumol's cost disease holds if, following a rise in productivity in the dynamic sector, (a) the relative price of the stagnant sector output increases (price increase); (b) the stagnant industry takes a rising share of nominal output (unbalanced growth); and (c) the changing composition of output across stagnant and dynamic industries reduces the effect of the productivity improvement on the average productivity (adverse effect on productivity).

To gain intuition, we start with a simplified version of the model developed in the previous section, where production in two sectors, manufacturing $(m)$ and housing $(h)$, requires only labor

$$
Y^{m}=a L^{m}, \quad Y^{h}=L^{h},
$$


and $a$ is the exogenous labor productivity in manufacturing. By perfect competition, profit maximization, and perfect labor mobility $W=q^{h}=a$, and per capita income is simply

$$
y=\left(Y^{m}+q^{h} Y^{h}\right) / L=\left(a L^{m}+a L^{h}\right) / L=a .
$$

Now consider a steady state with a constant per-capita demand of the housing stock, $h^{d}(\pi, W)$ where

$$
\begin{gathered}
W=a \\
\pi=q^{h}-(1-\delta) q^{h} /(1+r)=a\left(\frac{\delta+r}{1+r}\right)
\end{gathered}
$$

for some exogenously fixed rate of interest, $r$. Since housing is the only source of households' wealth and $q^{h}=y=a$, the wealth-to-income ratio is

$$
\beta(a) \equiv \frac{q^{h} h^{d}}{y}=h^{d}\left(a\left(\frac{\delta+r}{1+r}\right), a\right) .
$$

Then, the effect of a rising relative productivity on $\beta(a)$ depends on the elasticities of housing demand with respect to its own price $\left(\hat{h}_{\pi}^{d}\right)$ and wage income $\left(\hat{h}_{W}^{d}\right)^{5}$. In particular, the percentage change in $\beta$ generated by a 1 percent increase in $a$ is equal to the sum of these two elasticities

$$
\frac{\partial \beta / \beta}{\partial a / a}=\hat{h}_{\pi}^{d}+\hat{h}_{W}^{d}
$$

Observe that, with an homothetic representation of preferences, $\beta$ increases with $a$ if and only if housing demand is inelastic with respect to its own price, i.e., $-\hat{h}_{\pi}^{d}<1$. This condition squares with most empirical estimations. In fact, the general consensus is that both income and price elasticities are relatively small in absolute value, the first ranging between 0.5 to 1 , and the second between -1 and -0.5 (for example, Mayo

\footnotetext{
${ }^{5}$ From now on, to simplify the notation, we use a "hat" to denote partial elasticities, i.e., letting $h(x)$ be any differentiable function in $\mathbb{R}^{n}$, we let $\hat{h}_{x_{i}}=\partial \log h(x) / \partial \log x_{i}$.
} 
(1981) and Hansen et al. (1996)). In what follows, we show that this basic intuition extends to a more sophisticated life-cycle economy with capital and land.

Now we show how the above example generalizes to the two-sector overlapping generations economy with bequests and capital that we have introduced in the previous section. We restate the Baumol's cost disease result in the present framework as follows. Define housing wealth as $v \equiv q^{h} h$ and the average income per-capita as

$$
y=y^{m}(1-\lambda)+q^{h} y^{h} \lambda / a
$$

Since wealth includes capital and housing, the wealth-to-income-ratio is

$$
\beta=\frac{k+v}{y}=\beta^{k}+\beta^{h}
$$

where $\beta^{k}=k / y$ is the business capital and $\beta^{h}=v / y$ the housing component. Then, we say that there exists a housing cost disease if, at an equilibrium PBSS,

$$
\begin{array}{lll}
\text { (HA) } & \partial q^{h} / \partial a>0 & \text { (housing appreciation), } \\
\text { (IW) } & \partial \beta / \partial a>0 & \text { (increasing wealth-to-income ratio), } \\
\text { (IN) } & \partial b / \partial a>0 & \text { (increasing wealth inequality). }
\end{array}
$$

It turns out that the emergence of a cost disease in the present model depends on the properties of the demand side of the economy (demand elasticities) but also on the magnitude of relative capital intensities and factor shares. In the remaining part of this section we will provide a robust set of (plausible) conditions under which the set of phenomena from (HA) to (SP) are verified.

From the CES preference specification we derive that the elasticities of consumption and housing demand with respect to the user cost of housing, $\pi$, are independent of 
individuals' wealth. In particular,

$$
1+\hat{h}_{\pi}^{d}=(1-\gamma)\left(1-\phi^{h}\right), \quad \hat{s}_{\pi}=-(1-\gamma)\left(1+\left(1-\phi^{h}\right)\right) c^{y} / s
$$

where $c^{y}$ is the aggregate young-age consumption. In what follows we will be mostly concentrate on the case of an inelastic demand for housing, i.e., $\gamma<1$. As shown above, this implies that a rise in the user cost of housing generates, ceteris paribus, a rise in the demand for housing wealth and a fall in saving. On the contrary, if $\gamma=1$, then $\hat{h}_{\pi}^{d}=-1$ and $\hat{s}_{\pi}=0$.

Consider now the supply side of the model and define the sector-specific factor shares (or output elasticities)

$$
\mathcal{S}_{k}^{j}=f_{k}^{j} k^{j} / f^{j}, \quad \mathcal{S}_{z}^{h}=f_{z}^{h} z / f^{h}, \quad \mathcal{S}_{l}^{h}=1-\mathcal{S}_{k}^{h}-\mathcal{S}_{z}^{h} .
$$

Then, we let the capital intensity differential across the two sectors be defined as

$$
\Delta=\left(\frac{\delta+\zeta}{1+r}\right) \mathcal{S}_{k}^{h}\left(\frac{a k^{m}-k^{h}}{k^{h}}\right)
$$

Observe that $\Delta$ is a function of factor shares. In particular, $\mathcal{S}_{k}^{m}>\mathcal{S}_{k}^{h}$ is a necessary condition for the manufacturing sector to exhibit a higher capital intensity ${ }^{6}$, i.e., $\Delta>0$.

To see the role of factor shares and capital intensities, start with equation (28) and use the profit maximization condition (2) to express the share of labor in construction in terms of the housing value

$$
\lambda=\frac{(\delta+\zeta) \mathcal{S}_{k}^{h}}{(1+r) k^{h}} a v .
$$

\footnotetext{
${ }^{6}$ Note that $\mathcal{S}_{k}^{m}>\mathcal{S}_{k}^{h}$ if and only if the housing price $\left(q^{h}\right)$ is decreasing in the interest rate $(r)$.
} 
Using the above in (15) and (31), we obtain

$$
\begin{aligned}
k & =k^{m}-\Delta v \\
y & =y^{m}-\left((1+r) \Delta-(\delta+\zeta) \mathcal{S}_{z}^{h}\right) v, \\
\beta & =\left(k^{m}+(1-\Delta) v\right) / y .
\end{aligned}
$$

Equations (34)-(36) provide some intuition about the role of the assumed restrictions on the relative capital intensity for the housing cost disease. In particular, when $\Delta$ is positive and $\mathcal{S}_{z}^{h}$ is sufficiently small, all else unchanged, a larger housing wealth, $v$, decreases $k$ and $y$, and increases $\beta^{h}$, both directly and through a fall in $y$. Provided that $\Delta<1$, a higher $v$ may, in turn, generate a larger wealth-to-output ratio.

The next proposition summarizes the key results about the elasticities of the relevant equilibrium variables with respect to $a$ at a PBSS. From now on, we denote the elasticity of a variable $x$ with respect to $a$ at equilibrium as $\hat{x}_{a}^{*}$, where $x$ may be one of the steady state equilibrium values $v, k, b, q^{h}, \lambda, y$ or $\beta$. Evidently, these elasticities take into account the direct and indirect effects of a changing $a$.

Proposition 1. Assume that $0<\Delta<1$. Then, a PBSS (if it exists) is unique and it has the following properties.

- If $\gamma=1$ and $\sigma^{h}=1$, a change in a is allocation neutral, in the sense that the PBSS values $v, b, k, y, \lambda$ and $\beta$ are not affected by $a$.

- If, on the other hand, $\sigma^{h} \geq 1$ and $\gamma \leq 1$, with one strict inequality, and

$$
\Delta<1-\left(\frac{\delta+r}{1+r}\right) \frac{\phi^{y}}{\phi^{y}+\phi^{o}}
$$

then, we have $\hat{v}_{a}^{*}>0, \hat{b}_{a}^{*}>0$.

- Finally, for $\sigma^{h}$ close enough to 1 and small enough land share $\mathcal{S}_{z}^{h}$, we have (see the appendix for details) 


$$
\hat{y}_{a}^{*}<0, \hat{\beta}_{a}^{*}>0, \hat{k}_{a}^{*}<0 \text { and } \hat{\lambda}_{a}^{*}>0 .
$$

Hence, the unit-elastic economy, defined by $\sigma^{h}=\gamma=1$, is a benchmark case in which a change in $a$ generates no change in all the relevant variables. On the other hand, when the housing demand becomes relatively inelastic $(\gamma<1)$, an increase in a generates a reallocation of resources towards the housing sector. Namely, housing wealth and bequests are complementary and increase with the housing price. Observe that the rise in the housing price is independent of the land scarcity by the assumption that the land to labor ratio in the construction sector, $z$, is constant. If land permits were to increase less than proportionally relative to the amount of labor efficiency in construction, the impact of $a$ on $q^{h}$ would be magnified.

The assumptions used in the propositions are motivated by analytical tractability and by the objective to make the housing cost disease a likely outcome under some additional intuitive conditions. In particular, the assumption that the capital intensity in manufacturing is higher than in the construction sector is a key restriction for generating the rising wealth-to-income ratios that are part of the housing cost disease defined in this paper. The same is true for the assumption $\gamma<1$. The restriction $\Delta \in(0,1)$ guarantees a "well behaved" comparative statics for the system of equations defining a PBSS (local uniqueness). The reader can find more intuition and details in appendix A.I. In addition, $\Delta<1$ is a requirement for a meaningful steady state equilibrium when bequests are not too large. In particular, in section A.II of the appendix we show that this upper bound must be verified for the existence of an equilibrium with positive output in the construction sector, under the assumption that aggregate saving falls short of the wage bill.

What is the empirical support for the assumptions that we impose to generate a housing cost disease? In the literature, there is consistent support for the assumption that the construction sector is less capital intensive than manufacturing and little consensus on the most plausible values for the elasticity of substitution between capital 
and labor. In any case, it is important to stress that the above assumptions are not necessary, bur rather they provide with the most favorable environment for the housing cost disease. In particular, the low price elasticity in the demand for the output of the stagnant sector is one of the key assumption in Baumol (1967)'s model. We observe that there exists strong evidence that housing demand responds less than proportionally to a rise in price. In particular, Hanushek and Quigley (1980), Mayo (1981) and Ermisch et al. (1996) provide estimates of the housing demand elasticity in the range $(-0.8,-0.5)$. Similarly, Ngai and Pissarides (2007) assumes a low (i.e., below one) elasticity of substitution across final goods in order to show that employment is gradually shifting to sectors with low productivity growth. In our model, a rise in relative efficiency in manufacturing determines an increase in the relative price of housing with a small effect on the demand of this good. Therefore, the demand for housing wealth $(v=q h)$ increases with $a$ and we observe a reallocation of production and labor to the less productive sector. The assumption that $\Delta>0$ has no analogous counterpart in the literature following the Baumol's cost disease proposition.

\section{Quantitative Analysis}

In this section, first we evaluate the consequences of a rising relative efficiency in manufacturing on stationary equilibrium variables and show the impact of the housing cost disease on housing prices, wealth ratios and inequality under more general assumptions. In particular, we assume Cobb-Douglas technology in manufacturing, and CES with elasticity of substitution $\sigma^{h}$ in construction. Second, we consider the special case of Cobb-Douglas technology in both sectors and look at the transition between two different steady states.

Table 1 reports all the parameters used in the comparative static between different steady states. Preferences are of the CES class as defined in equation (23). We set the 
coefficients of the CES utility function in order to match the expenditure shares $\phi^{j}$, for $j=y, o, h$, to some stylized facts for the US economy. First, we set $\chi^{h}=0.20$ to match the US households expenditure on housing services (approximately $15 \%$ of 2015 GDP according to the BEA NIPA Table 2.3.5). To calibrate the coefficients attached to the consumption expenditure of young $\left(\chi^{y}\right)$ and old $\left(\chi^{o}\right)$ individuals we use the fact that, in the US in 2014, older people (aged 65 or more) are approximately $13 \%$ of the population (World Development Indicators from World Bank Data). Assuming that the consumption shares of young and old follow their shares in the population we set the weights $\chi^{y}$ and $\chi^{o}$, respectively, to 0.70 and 0.10 . Following Ogaki and Reinhart (1998), we set the elasticity of inter-temporal substitution for the households' preferences, $\gamma$, to a number smaller than 1 and, in particular, equal to $0.5^{7}$. Recall that in the PBSS, for the two-type of households' case (i.e., rich and poor), described in section 3, the real interest rate is pinned down by the preference for altruism of the rich household. We set the real interest rate to match the average real return on US Treasury of about $1.5 \%$ per year. Therefore, for a holding period of 25 years, corresponding to a generation, we set $r=0.28$. The depreciation of the housing stock is set equal to $\delta=20 \%$, implying complete depletion over five generations as in Deaton and Laroque (2001). We use O'Mahony and Timmer (2009)'s KLEMS data to have rough estimates of the capital factor shares in construction and manufacturing in the US over the 1970-2010 period and, accordingly, set $\alpha^{m}=0.40$ and $\alpha^{h}=0.10$. These numbers are in line with those in Valentinyi and Herrendorf (2008) who set the capital share in manufacturing and construction respectively to 0.4 and 0.2 . Therefore, the empirical evidence supports our assumption that the manufacturing sector is more capital intensive than the housing sector. Note that while technology in manufacturing

\footnotetext{
${ }^{7}$ Note that if $\gamma=0.5$, the inter-temporal elasticity of substitution is smaller than 1 . In order to match asset prices data Bansal et al. (2008) use a relatively high value of 1.5. Previous literature had estimated a much lower value, closer to zero, through direct estimates of the first order conditions of the solution of the optimal intertemporal consumer problem (cf. (Hall, 1988)). Standard RBC literature has been used a value of 0.66, estimated by Kydland and Prescott (1982).
} 
is Cobb-Douglas, we assume a more general CES specification for the housing sector. Therefore, while $\alpha^{m}$ corresponds to the model implied capital share of manufacturing output, $\alpha^{h}=0.10$ is only approximately corresponding to the capital share in housing production. Similarly, we set the weight attached to the land input to $\eta^{h}=0.10$, which is the same value used by Davis and Heathcote (2005). Neels (1982) provides an estimate of the output elasticity of land (i.e., our measure of $\mathcal{S}_{z}^{h}$ ) between 0.03 and 0.06, while Knoll et al. (2017) considers a even larger value and argue that the land share of value added in construction is large, and close to $50 \%$. There is no consensus in the empirical literature on the value of the elasticity of substitution between capital and labor. For example, while Piketty and Zucman (2014) assume a value greater then one, Antras (2004) find values smaller than 1 and Chirinko (2008) defines a range of values between 0.4 and 0.6. Regarding the elasticity between land and capital, Ahlfeldt and McMillen (2014) find values close to 1 . We assume the same value for the elasticity between capital and labor, and capital and land, in the housing sector and set it to $\sigma^{h}=1.5$. Finally, we set the population's growth rate to $n=0 \%$ and the steady state growth rate of labor augmenting productivity in each sector to $g=0.65$, implying an annual growth rate of 2 percent. As discussed in section 3, we assume a land policy such that $z$ is invariant. We leave for future work the analysis of a change in the land supply and of population growth on wealth ratios, housing and land prices, and inequality.

We are interested in evaluating the long-run effects of productivity improvements and figures 1 summarize our main results. According to our estimates using O'Mahony and Timmer (2009)'s KLEMS data, on average, across the eight largest developed economies, relative labor efficiency in manufacturing increased approximately by 75 percent between 1970 to $2010^{8}$. Therefore, we plot the percentage changes in the

\footnotetext{
${ }^{8}$ See the discussion in section 6 and the separate online appendix available on our web sites for details on the estimation of the relative labor efficiency, and a country breakdown of its evolution over the period 1970-2010, using O'Mahony and Timmer (2009)'s KLEMS data.
} 


\section{Table 1: Model's Parameters}

\begin{tabular}{lll}
\hline Preferences & & \\
Weight consumption young: & $\chi^{y}$ & 0.70 \\
Weight consumption old: & $\chi^{o}$ & 0.10 \\
Weight housing services: & $\chi^{h}$ & 0.20 \\
Elasticity of substitution preferences: & $\gamma$ & 0.50 \\
Interest rate: & $r$ & 0.67 \\
Technology & & \\
Housing depreciation: & $\delta$ & 0.20 \\
Capital share in housing: & $\alpha^{h}$ & 0.10 \\
Land share in housing: & $\eta^{h}$ & 0.10 \\
Capital share in manufacturing: & $\alpha^{m}$ & 0.40 \\
Elasticity of substitution housing: & $\sigma^{h}$ & 1.50 \\
Economy structure & & \\
Population growth rate: & $n$ & 0.00 \\
Sectoral productivity growth rate (\%): & $g$ & 0.65 \\
\hline
\end{tabular}

Notes: This table reports the parameters used to simulate the model for different steady-states corresponding to different values of the exogenous relative efficiency in manufacturing $a$. For robustness, we also run simulations for values of $\sigma^{h}=1$ (i.e., Cobb-Douglas technology). The real interest rate $r$ corresponds to a holding period equal to a generation.

steady-state values of the main variables of the model for different levels of the relative efficiency in manufacturing $a=1, \ldots, 1.75$ with respect to their values when $a=1$. We consider two different cases for the elasticity between inputs in the construction sector: in our baseline specification $\sigma^{h}$ is greater than one and equal to 1.5 (red-dashed line); alternatively, we consider the case of $\sigma^{h}=1$, i.e., Cobb-Douglas (blue-solid line). We find that total wealth and housing wealth increase with the improvements in relative productivity (by 7.5 and 27 percent respectively for the baseline case). On the contrary, business capital declines by approximately 3 percent. The large increase in housing wealth goes along a strong increase in the housing price (approximately 60 percent), and labor share in construction (approximately 25 percent) as labor moves toward the relatively stagnant sector. Note that, despite the large increase in the simulations, housing wealth as a share of total wealth stays always below 50 percent, in line with data. Similarly, despite the strong rise in $\lambda$, the share of workers in construction 
remains close to 5 percent in all cases.

Finally, we plot total bequests, our measure of inequality, as a fraction of total income. Bequests increase modestly with the improvements in relative productivity (approximately 3.5 percent). In the eight largest advanced economies, over the period 1970-2010, national wealth-to-income increased by approximately 60 percent, housing wealth by 112 percent and real housing prices by 53 percent and, in some countries like Italy and France, close to 100 percent. Therefore, our model is able to explain a fraction of the historical increase of these variables without relying on alternative, in our view complementary, explanations like skilled-biased technological change, the role of equity and financial markets, and less progressive tax systems. In addition, we have de facto shut down the effect of land scarcity and population growth which are also likely to have a role.

Figure 1: Comparative statics: response to an increase in $a$
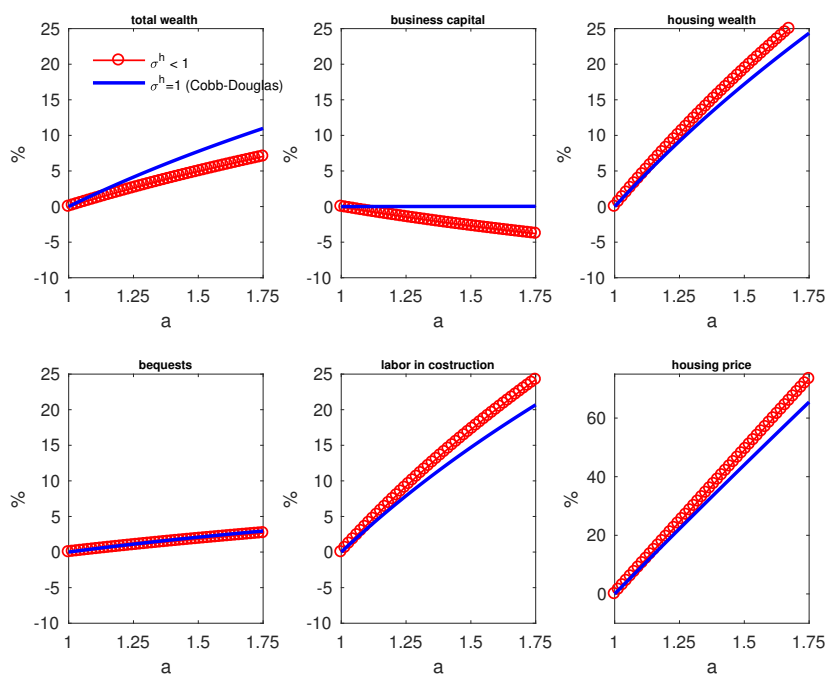

Notes: This figure plots the percentage changes in the steady-state values of total $(\beta)$, housing $\left(\beta^{h}\right)$, and non-housing $\left(\beta^{k}\right)$ wealth-to-income ratios; the bequests-to-income ratio $(b / y)$, the share of workers in construction $(\lambda)$ and the housing price $\left(q^{h}\right)$ for different values of the relative productivity sector $a=1, \ldots, 1.75$, with respect to their value when $a=1$. The red-dashed line is for the baseline value of the elasticity of substitution in the housing sector, $\sigma^{h}=1.5$. The blue solid lines corresponds to Cobb-Douglas technology in the housing sector $\left(\sigma^{h}=1\right)$. Note that only for housing price the upper limit of the vertical axis is 75 , while in all the other plots is 25 .

Note that the fact that our model is fairly stylized has some costs. For example, 
our 2-type assumption implies that only a very small fraction of the population leaves any bequests and drives wealth inequality. Furthermore, while our numerical exercise compares different steady-states, the long-run trends in the data might combine different steady states and transitions within a given steady-state. In what follows, we look in greater detail at the transition between two different steady states. For the sake of simplicity, we consider the model laid out in section 2 , but assume that production functions in manufacturing and housing are both Cobb-Douglas. We further assume that the economy starts from a level of relative productivity equal to $a_{0}$ and moves toward a higher level $a>a_{0}$, with $a>1$ according to the following law of motion

$$
\ln a_{t+1}=\mu \ln a_{t}+(1-\mu) \ln a .
$$

We log-linearize the model around the new steady state, function of $a$, and study the transition to $a$ starting from a lower level of the relative productivity equal to $a_{0}$. We set the initial values of the predetermined variables (i.e., the levels of capital and bequest) to their steady state values at $a_{0}$ and study the adjustment toward $a$. All the main parameters are the same as in table 1 . In figure 2 we present our results. Relative manufacturing productivity starts about 20 percent below the new steady state and converges to $a$ at the exogenous rate $\mu=0.8$. The housing price $(q)$, the value of the stock of housing $(v)$ and the level of bequests $(b)$ all increase in the adjustment to the new steady state.

In this section, we presented quantitative results of the model showing that it generates a strong housing cost disease. Despite the fact that manufacturing sector represents a small share to total valued added, changes in relative labor-augmenting efficiency have the potential to generate large long-run increases in housing prices and wealth ratios. In the next section, we evaluate the empirical support of our main conjecture using a sample of advanced economies. 
Figure 2: Transition between steady states: response to an increase in $a$
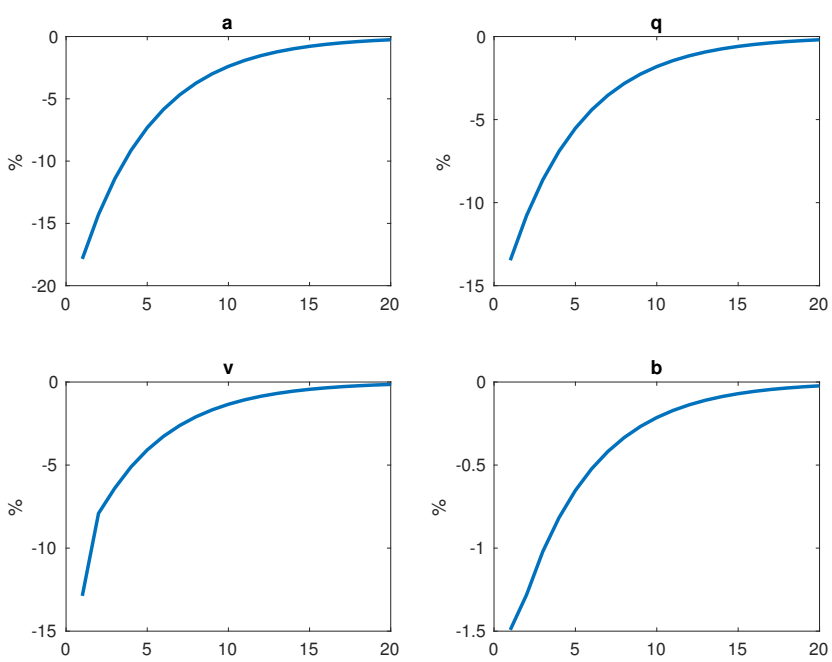

Notes: The figure reports the dynamics of the relative manufacturing productivity $(a)$, housing price $(q)$, value of housing stock $(v)$, and level of bequests $(b)$ in the adjustment to a new steady state characterized by $a>1$ starting from a lower value $a_{0}<a$. The horizontal axis denotes time-periods. All variables are in log difference with respect to their steady state values. The dynamics is obtained by a version of the model described in section 2, with Cobb-Douglas production functions in both sectors, linearized around the new steady state. The initial values of the predetermined variables are those corresponding to the steady state under $a_{0}$.

\section{Empirical Estimation}

In this section, we show that, in a panel of advanced economies, a long-run increase in the relative productivity in the rest of the economy with respect to construction is associated with an increase in the wealth-to-income ratio. We collect annual wealth data from Piketty and Zucman (2014), who have put together an incredibly rich dataset on wealth and income, starting from national accounts data, for the period 1970-2010, for the largest eight developed economies: the United States, Germany, the United Kingdom, Canada, Japan, France, Italy and Australia ${ }^{9}$. All assets and liabilities are valued at prevailing market prices. Private wealth is net wealth of households, and assets include all non-financial and financial assets. Public wealth is net wealth of public administrations and government agencies. National wealth is the sum of private and

\footnotetext{
${ }^{9}$ For a smaller subset of countries, Piketty and Zucman (2014) provide longer time-series. However, we choose to restrict our focus on a time-period for which we could maximize the number of countries in the sample and with more reliable data. For additional details on the data refer to the online appendix to this paper or directly to Piketty and Zucman (2014).
} 
public wealth. While the financial component of private wealth includes households' holdings of domestic public debt, at the national level holdings of domestic debt are netted out. Housing wealth is one of the components of total wealth, and it measures the net value of households' real-estate holdings ${ }^{10}$. As public debt should not be part of individuals' net (of the present value of future taxes) wealth over the long run, in this section we focus on national, rather than private, wealth, and on one of its main component, namely housing wealth, while we present data on private wealth in a separate online appendix available on our web sites. We combine data on wealth ratios, for the eight largest advanced economies, with data on relative productivity in the rest of the economy with respect to construction, estimated from the O'Mahony and Timmer (2009)'s EU KLEMS Growth and Productivity Accounts. For some of the countries in the sample data start after 1970: in this case, we extend the series by linear interpolation to obtain a balanced panel, but results of the unbalanced panel, presented in the online appendix, are virtually unchanged. Since manufacturing is only a small share of total value added (i.e., approximately $13 \%$ in the US), we estimate relative productivity by feeding data on gross value added, capital and labor inputs, to the production functions of each sector defined in (1) and considering "Total industries" (TOT) as the empirical counterpart for the rest of the economy ${ }^{11}$. In particular, relative labor efficiency is estimated under the assumption of Cobb-Douglas production function in the general economy, and CES with elasticity smaller than unity in construction.

In the eight largest economies, national wealth increased substantially more than income over the period 1970 to 2010. In particular, the national wealth-to-income ratio

\footnotetext{
${ }^{10}$ Note that in the computation of net housing wealth, financial liabilities, such as mortgages, are netted out the housing stock value. On the contrary, in the model $v$ denotes gross housing wealth. It is possible to show that, in the model, poor households have lower financial wealth than the rich and they are borrowers when $1+\phi^{o} / \phi^{h}<(1+g)(r+\delta) /(1+r)$ a condition that can be verified only if $g>(1-\delta) /(r+\delta)$.

${ }^{11}$ In KLEMS's data, "total industries" include all the sectors of the economy. Note that, following the technological assumptions spelled out in section 2, we assume that productivity is laboraugmenting, rather than affecting all the factors of production. Therefore, we are implicitly capturing relative changes in the quality of labor in different sectors of the economy.
} 
increased by about 60 percent. Interestingly, housing wealth increased even more, on average by about 112 percent. There exist important cross-country differences. For example, Italy is the country with the largest increase in the ratio between both national and housing wealth-to-income: 135 and 218 percent, respectively. On the contrary, in the US the national wealth-to-income ratio increased only by 6 percent, while housing wealth-to-income decreased by about 19 percent $^{12}$. Since wealth is typically unevenly distributed, it is not surprising that, over the same period, income and wealth inequality increased along with the wealth-to-income ratio. In particular, using data in Alvaredo et al. (2016)'s Top World Income Database, we note that, on average, the shares going to the top 1 and 10 percent of the income distribution increased, respectively, by 46 and 20 percent. Similarly, also the shares going to the top 1 and 10 percent of the wealth distribution increased, by approximately 18 and 7 percent. While the US is the country with the smallest increase in the wealth-to-income ratio, it is also the country with the largest increase in both income and wealth inequality. In fact, the shares going to the top 1 and 10 percent of the income distribution increased, respectively, by 123 and 47 percent; those going to the top 1 and 10 percent of the wealth distribution increased, respectively, by 20 and 11 percent.

We plot in figure 3 our estimates for the relative labor efficiency, both for the case of unitary elasticity of substitution in housing production (green line), and elasticity smaller than one and equal to $\sigma^{h}=0.6$ (black line). With the exception of Italy, the effect of $\sigma^{h}$ on our estimates is second order. The US, Japan and Italy are the countries with the largest increase in relative efficiency, in the period 1970-2010. In the rest of the countries in our sample the increase is more modest.

In order to evaluate the empirical support to our conjecture, we estimate a panel in which we relate the averages over seven years of national wealth ratios and relative

\footnotetext{
${ }^{12}$ In the separate online appendix we show that these figures are robust to ending the sample in 2007, before the Great Recession, and to computing percentage changes using five-year averages at the beginning and end of the sample.
} 
Figure 3: Relative Labor Efficiency in Manufacturing
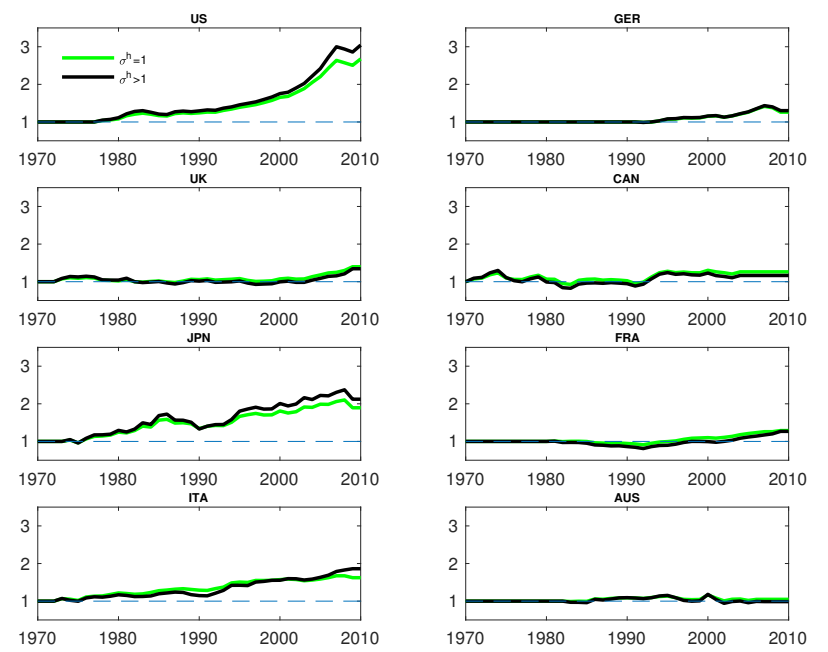

Notes: This figure plots two measures of relative labor efficiency in the rest of the economy, with respect to the construction sector, for the US, Germany, the UK, Canada, Japan, France, Italy and Australia for the period 19702010. Relative labor efficiency is estimated as residual assuming Cobb-Douglas technology in manufacturing, and either Cobb-Douglas (green lines) or CES (black lines) technology in housing construction. The elasticity of substitution for the CES technology is set to $\sigma^{h}=1.5$. All series are normalized to 1 in 1970 .

productivities. Table 2 summarizes the main results. In particular, in regressions (1)-(4) all variables are averages over non-overlapping seven years periods (i.e., 197670, 1983-77, 1990-84, 1997-91, 2005-98). In regression (5), we instead directly use yearly data and extend the sample to 2010. In regression (1) we estimate a panel with country fixed effect and relative productivity as the only regressor. The coefficient on relative productivity is large and significant at the $5 \%$ level indicating that unbalanced growth of productivity in manufacturing is associated to an increase in the national wealth ratios. In regression (2) we use robust standard errors clustered at the country level and show that the coefficient on relative productivity is still significant at the 5 percent level. In regression (3) we introduce time fixed-effect, which absorbs part of the explanatory power of relative productivity. In fact, the coefficient drops from 3.78 to 2.24 and coefficient is significant only at the 15 percent confidence level. In regression (4) we include additional regressors, that further absorbs the explanatory power of relative productivity: the coefficient drops to approximately 2 but remains 
significant at the 10 percent confidence level $\%{ }^{13}$. In particular, we include the log of the population, the growth rate of real income, the private saving rate and the real capital gains in national wealth. All these additional regressors are not statistically significant. Finally, in regression (5) we estimate the full model on yearly data. The coefficient on relative productivity is smaller, but statistically significant at the 10 percent level. Therefore, our panel estimates provide empirical support for the housing cost disease conjecture, even though we note that standard errors are large in part because of the small number of countries in the sample.

Our empirical findings are subject to several issues. First, the sample's small number of countries and limited time-length. Second, possible measurement errors in both Piketty and Zucman (2014) and O'Mahony and Timmer (2009)'s data and our measure of relative labor efficiency. Third, we do not control for alternative explanations of the long-run increase in wealth ratios which we consider complementary, rather than competitive, to our story. In the separate online appendix we address some of these issues, for example by considering the relationship between housing prices, a key driver of housing wealth, and relative productivity improvements, for a larger sample of sixteen OECD countries.

In the next section, we evaluates the implications of the housing cost disease in terms of welfare.

\section{Welfare}

In this section we address the housing cost disease problem from a welfare point of view and try to evaluate whether, according to our model, the fact that housing takes a large share of private wealth is undesirable.

\footnotetext{
${ }^{13}$ Note that we use robust standard errors clustered at the country level to account for possible autocorrelation of the residuals and heteroskedasticy. However, as the number of countries is small, clustered standard errors could increase the likelihood of failing to reject the null when the null is false. In the separate online appendix we show that standard errors not clustered at the country level tend to be lower.
} 
Table 2: Panel Estimation

\begin{tabular}{|c|c|c|c|c|c|}
\hline VARIABLES & $\begin{array}{c}(1) \\
\text { NWI }\end{array}$ & $\begin{array}{c}(2) \\
\text { NWI }\end{array}$ & $\begin{array}{c}(3) \\
\text { NWI }\end{array}$ & $\begin{array}{c}(4) \\
\text { NWI }\end{array}$ & $\begin{array}{c}(5) \\
\text { NWI }\end{array}$ \\
\hline RTFP & $\begin{array}{c}3.781^{* * *} \\
(0.707)\end{array}$ & $\begin{array}{c}3.781^{* * * *} \\
(0.778)\end{array}$ & $\begin{array}{l}2.243^{*} \\
(1.333)\end{array}$ & $\begin{array}{c}2.033^{* *} \\
(1.120)\end{array}$ & $\begin{array}{c}0.493^{* *} \\
(0.286)\end{array}$ \\
\hline LPOP & & & & $\begin{array}{c}0.198 \\
(1.586)\end{array}$ & $\begin{array}{l}-0.273 \\
(0.483)\end{array}$ \\
\hline GRI & & & & $\begin{array}{c}-2.437 \\
(13.771)\end{array}$ & $\begin{array}{c}-4.276^{* * *} \\
(1.698)\end{array}$ \\
\hline PSR & & & & $\begin{array}{l}-3.018 \\
(3.580)\end{array}$ & $\begin{array}{c}-2.652^{* * *} \\
(1.082)\end{array}$ \\
\hline CAPG & & & & $\begin{array}{c}1.277 \\
(5.452)\end{array}$ & $\begin{array}{c}2.497^{* * *} \\
(0.878)\end{array}$ \\
\hline Observations & 40 & 40 & 40 & 40 & 328 \\
\hline R-squared & 0.480 & 0.480 & 0.639 & 0.651 & 0.640 \\
\hline Number of id & 8 & 8 & 8 & 8 & 8 \\
\hline Country FE & YES & YES & YES & YES & YES \\
\hline TIME FE & NO & NO & YES & YES & YES \\
\hline Clustered SE & NO & YES & YES & YES & YES \\
\hline YEARS & 1970-05 & 1970-05 & 1970-05 & 1970-05 & $1970-10$ \\
\hline FREQ. & 7 years & 7 years & 7 years & yearly & 7 years \\
\hline
\end{tabular}

Notes: The dependent variable is national wealth-to-income (NWI). The regressors are the relative productivity in manufacturing (RTFP), the log of the population (LPOP), the rate of growth of real income (GRI), the private saving rate (PSR), and the real capital gains on national wealth (CAPG). In columns 1 to 4 all the variables are averages over 7 years non overlapping time periods. In column 5 we use yearly values.

Within a similar overlapping generations model, Deaton and Laroque (2001) find that the presence of a demand for housing in a growing economy generates a portfolio reallocation away from capital and towards housing, causing the accumulation of capital to fall short of the Golden Rule level, and they consider this as possible reason for confiscating property and giving it to consumers at no charge. It should be noted, however, that allocations departing from the Golden Rule are inconsistent with a social optimum only if we endorse a specific social welfare criterion, such as a weighted sum of all generations' utilities with rate of time preference equal to the population growth 
rate. In fact, any market allocation at which the rate of interest is larger than the population growth rate is Pareto optimal and, in these cases, reducing the value of the housing stock may have adverse effects on some generation's welfare. Conversely, when the real interest rate falls short of the population growth rate, a case that, in our model, can only occur with zero bequests, Pareto improvements can be obtained by decreasing investment in housing as well as in the capital stock. In other words, the crowding-out of capital induced by housing demand and the inter-generational transfers may, in fact, be desirable to avoid an over-accumulation of capital. Piketty (2014) advocates a tax on wealth based on the argument that a rising wealth to income ratio may lead to increasing inequality.

In any case, there are a number of reasons why a welfare analysis may be interesting. First, since rising housing prices generate more bequests and wealth inequality, the housing cost disease may be social welfare diminishing from an egalitarian perspective (although, due to heterogeneous discount rates, some inequality is compatible with an egalitarian planning optimum). Second, since, in a competitive equilibrium, poor households would like to force gifts from children and, therefore, leave no bequests because of one-sided altruism, raising the poor old individuals' wealth may improve social welfare. Then, a rise in housing prices may relax the non-negativity constraint on bequest values and generate the increase in old age consumption that the market is preventing under one-sided altruism. Third, a housing appreciation may decrease welfare as it makes housing less affordable.

We compute the effect of an unanticipated rise in the level of the relative labor efficiency, $a=A^{m} / A^{h}$, at $t=0$, at a stationary equilibrium such that the poor-type households leave zero bequests and the rich-type leave positive bequests at all periods (i.e., PBSS). Recall that, for all households of type $i$ born at time $t \geq 0$, welfare is measured by

$$
V^{t, i}=u\left(C_{t}^{y, i}, C_{t+1}^{o, i}, H_{t+1}^{i}\right)+\left(\theta_{i}(1+n)\right) V^{t+1, i}
$$


Assuming (as in section 3) that $u($.$) is homothetic, \theta^{i}(1+\zeta)<1$, and recalling the notation

$$
c^{y, i}=C^{y, i} / A_{t}^{m}, \quad C_{t}^{o, i} / A_{t}^{m}=c^{o, i}, \quad h^{i}=H_{t}^{i} / A_{t}^{m},
$$

we derive the steady state evaluation of dynasty $i$ 's welfare as

$$
V^{i}=\frac{u\left(c^{y, i},(1+g) c^{o, i},(1+g) h^{i}\right)}{1-\theta_{i}(1+\zeta)}
$$

where the above time invariant variables are computed at the PBSS with $1+r=1 / \theta_{r}$. The effect of a rise in the relative productivity on the steady state households' welfare is, then,

$$
\frac{\partial V^{i}}{\partial a}=\mu^{i}\left(\frac{\partial c^{y, i}}{\partial a}+\frac{u_{2}^{i}}{u_{1}^{i}}(1+g) \frac{\partial c^{o, i}}{\partial a}+\frac{u_{3}^{i}}{u_{1}^{i}}(1+g) \frac{\partial V^{i}}{\partial a}\right)
$$

where $\mu^{i}=u_{1}^{i}\left(1-\theta_{i}(1+\zeta)\right)^{-1}$. Now recall that the households' lifetime budget constraint at steady state and the first order conditions from utility maximization imply

$$
c^{y, i}+(1+g) c^{o, i} /(1+r)+(1+g) q^{h}(r+\delta) h^{i} /(1+r)=w+b^{i}(r-\zeta) /(1+r),
$$

and $u_{2}^{i} / u_{1}^{i}=1+r, u_{3}^{i} / u_{1}^{i}=q^{h}(r+\delta) /(1+r)$. Then, using these in (38), we derive

$$
\frac{\partial V^{i}}{\partial a}=\mu^{i}\left(\frac{1+\zeta}{1+r}\right)\left(\left(\frac{r-\zeta}{1+\zeta}\right) \frac{\partial b^{i}}{\partial a}-\left(\frac{r+\delta}{1+n}\right) h^{i} \frac{\partial q^{h}}{\partial a}\right)
$$

Therefore, for the poor household, a housing price appreciation following an improvement in the level of manufacturing productivity relative to construction, $a$, is always welfare reducing, whereas it can be welfare augmenting for the rich households only if equilibrium bequests are positively affected by $a$. Observe, however, that the above evaluation only considers the lifetime welfare of the young generations at steady state. A complete welfare analysis should take into account the effect of a rising $a$ on the 
old households at the time in which this productivity shock is occurring. Since old individuals' housing ownership was acquired in young age, the change in $a$ does not affect the amount of their own housing stock and services, but a higher housing price increases their wealth allowing for higher old age consumption and bequests. Provided that their financial wealth is not too large, the cohort of initial old households are likely to gain.

\section{Conclusions}

In this paper we show that a Baumol's cost disease could complement alternative existing theories in explaining the increase in total and housing wealth-to-income ratios and wealth inequality that took place in the eight largest advanced economies in the last forty years. To show this, we have employed a simple life-cycle model with no financial frictions, two sectors (construction and manufacturing) and one-sided parental altruism. Key assumptions are that the construction sector is less capital intensive than manufacturing and housing demand sufficiently inelastic. Under these assumptions, a rise in labor efficiency in manufacturing produces a strong upward pressure on housing prices, a rise in the total and housing wealth-to-income ratios and a rise in bequests. The increase in housing valuations can possibly mitigate (relative to the First Best level) the beneficial effects of a rising productivity in manufacturing under an egalitarian welfare criterion when market allocations imply high enough consumption inequality and low enough heterogeneity in parental altruism. The empirical evidence supports our theoretical findings: there exists a positive link between relative productivity in the general economy, with respect to construction, and wealth ratios in the eight largest economies in the period 1970-2010. 


\section{References}

Ahlfeldt, Gabriel M. and Daniel P. McMillen, "New Estimates of the Elasticity of Substitution of Land for Capital," February 2014.

Alvaredo, Facundo, Anthony B. Atkinson, Thomas Piketty, Emmanuel Saez, and Gabriel Zucman, "The World Wealth and Income Database," 2016. http://www.wid.world.

Antras, Pol, "Is the US aggregate production function Cobb-Douglas? New estimates of the elasticity of substitution," Contributions in Macroeconomics, 2004, 4 (1).

Auerbach, Alan J. and Kevin Hasset, "Capita Taxation in the 21st Century," January 2015. NBER Working Paper 20871.

Bansal, Ravi, Dana Kiku, and Amir Yaron, Risks for the long run: Estimation and inference, Wharton School, University of Pennsylvania, 2008.

Baumol, William, "Macroeconomics of Unbalanced Growth: The Anatomy of Urban Crisis," American Economic Review, June 1967, 57 (3), 415-426.

Benhabib, Jess, Alberto Bisin, and Shenghao Zhu, "The Distribution of Wealth and Fiscal Policy in Economies with Finitely Lived Agents," Econometrica, 2011, 79 (1), 123-157.

_, _, and _ , "The wealth distribution in Bewely models with capital income risk," Journal of economic theory, 2015, 159, 459-515.

Bonnet, Odran, Pierre-Henri Bono, Guillaume Chapelle, and Etienne Wasmer, "Le capital lodgement contribute-t-il aux inégalités?," April 2014. LIEPP Working Paper.

Cagetti, Marco and Mariacristina De Nardi, "Entrepreneurship, frictions, and wealth," Journal of Political Economy, 2006, 114 (5), 835-870.

Castaneda, Ana, Javier Díaz-Gimènez, and José-Víctor Ríos-Rull, "Accounting for U.S. earnings and wealth inequality," Journal of Political Economy, 2003, 111 (4), 818-857.

Chirinko, Robert S, " $\sigma$ : The long and short of it," Journal of Macroeconomics, 2008, 30 (2), 671-686. 
Davis, Morris A. and Jonathan Heathcote, "Housing and the Business Cycle," International Economic Review, 2005, 46 (3), 751-784.

De Nardi, Mariacristina and Fang, "Wealth Inequality, Family Background, and Estate Taxation," March 2015. mimeo.

Deaton, Angus and Guy Laroque, "Housing, Land Prices, and Growth," Journal of Economic Growth, June 2001, 6, 87-105.

Ermisch, John F., Jeanette Findlay, and Kenneth Gibb, "The Price Elasticity of Housing Demand in Britain: Issues of Sample Selection," Journal of Housing Economics, 1996, 5, 64-86.

Favilukis, Jack, Sydney C. Ludvigson, and Stijn Van Nieuwerburgh, "The Macroeconomic Effects of Housing Wealth, Housing Finance, and Limited Risk Sharing in General Equilibrium," 2015. Journal of Political Economy (forthcoming).

Gale, William G. and John Karl Scholz, "Intergenerational transfers and the accumulation of wealth," Journal of Economic Perspectives, 1994, 8 (4), 145-160.

Galor, Oded and Joseph Zeira, "Income Distribution and Macroeconomics," Review of Economic Studies, January 1993, 60 (1), 35-52.

Gourinchas, Pierre-Olivier and Jonathan A. Parker, "Consumption over the life cycle," Econometrica, January 2002, 70 (1), 47-89.

Grossmann, Volker and Thomas Steger, "Das House-Kapital: A Theory of Wealth-to-Income Ratios," April 2016. CESifo Working Papers No. 5844.

Hall, Robert E, "Intertemporal substitution in consumption," Journal of political economy, 1988, 96 (2), 339-357.

Hansen, Julia L., John P. Formby, and James W. Smith, "The Income Elasticity of Demand for Housing: Evidence from Concentration Curves," Journal of Urban Economics, 1996, 39, 173-192.

Hanushek, Eric A. and John M. Quigley, "What is the Price Elasticity of Housing Demand?," Review of Economics and Statistics, 1980, 62, 449-454.

Hendricks, Lutz, "How important is discount rate heterogeneity for wealth inequality?," Journal of Economic Dynamics and Control, September 2007, 31 (9), 3042 3068 . 
Hsieh, Chang-Tai and Enrico Moretti, "Why Do Cities Matter? Local Growth and Aggregate Growth," April 2015. University of Chicago Working Paper.

Iacoviello, Matteo, "House prices, borrowing constraints, and monetary policy in the business cycle," American Economic Review, June 2005, 95 (3), 739-764.

_ and Stefano Neri, "Housing Market Spillovers: Evidence from an Estimated DSGE," American Economic Journal: Macroeconomics, April 2010, 2, 125-164.

Kahn, James A., "What drives housing prices?," Federal Reserve Bank of New York Staff Reports, 2008, (345).

Knoll, Katharina, Moritz Schularick, and Thomas Steger, "No price like home: global house prices, 1870-2012," The American Economic Review, 2017, $10^{\text {r }}$ (2), $331-353$.

Krusell, Per and Anthony A. Smith, "Income and Wealth Heterogeneity in the Macroeconomy," Journal of Political Economy, October 1998, 106 (5), 867-896.

Kydland, Finn E and Edward C Prescott, "Time to build and aggregate fluctuations," Econometrica: Journal of the Econometric Society, 1982, pp. 1345-1370.

Leung, Charles, "Macroeconomics and housing: a review of the literature," Journal of Housing Economics, 2004, 13 (4), 249-267.

Li, Bin and Zhixiong Zeng, "Fundamentals behind house prices," Economics Letters, 2010, 108 (2), 205-207.

Mayo, Stephen K., "Theory and Estimation in the Economics of Housing Demand," Journal of Urban Economics, 1981, 10, 95-116.

Moro, Alessio and Galo Nuno, "Does total-factor productivity drive housing prices? A growth accounting exercise for four countries," Economics Letters, 2012, $115,221-224$.

Neels, Kevin, "Specification Bias in Housing Production Functions," 1982. Rand note.

Ngai, Rachel L. and Christopher Pissarides, "Structural Change in a Multisector Model of Grwoth," American Economic Review, March 2007, 97 (1), 429-443.

OECD, OECD Economic Surveys, Paris: OECD Publishing, 2012. 
Ogaki, Masao and Carmen M Reinhart, "Measuring intertemporal substitution: The role of durable goods," Journal of Political Economy, 1998, 106 (5), 1078-1098.

O'Mahony, Mary and Marcel P. Timmer, "Output, Input and Productivity Measures at the Industry Level: the EU KLEMS Database," Economic Journal, 2009, 119 (538), F374-F403.

Piketty, Thomas, Capital in the Twenty-First Century, Cambridge, Massachusetts: Belknap Press - Harvard, 2014.

_ and Emmanuel Saez, "Inequality in the long run," Science, May 2014, 344 (6186).

- and Gabriel Zucman, "Capital is Back: Wealth Income Ratios in Rich Countries 1700-2010," Quarterly Journal of Economics, 2014, 129 (3), 1255-1311.

Quadrini, Vincenzo, "Entrepreneurship, saving, and social mobility," Review of Economic Dynamics, 2000, 3 (1), 1-40.

Rognlie, Matthew, "A Note on Piketty and diminishing returns to capital," 2014. mimeo.

Summers, Larry, "The Inequality Puzzle," Democracy A Journal of Ideas 2014. Summer.

Valentinyi, Akos and Berthed Herrendorf, "Measuring Factor Income Shares at the Sector Level," Review of Economics Dynamics, October 2008, 11, 820-835.

Weil, David N., "Capital and Wealth in the 21st Century," 2015. NBER Working Paper 20919. 


\section{Appendix (for publication) $)^{\dagger}$}

\section{A Comparative Statics}

\section{A.I Proof of proposition 1}

We reduce the whole equilibrium system at a PBSS to two equations and two unknowns. The two equations are the market clearing condition in the housing market and the capital market equilibrium; the two unknowns are the rich households' bequests, $b$, and the value of housing wealth, $v$. In particular, by equation (28), (28), we derive

$$
\begin{aligned}
\lambda & =\left(\frac{\delta+\zeta}{1+r}\right) a v \frac{\mathcal{S}_{k}^{h}}{k^{h}} \equiv \lambda(v, a), \\
k & =k^{m}-\lambda(v, a)\left(k^{m}-k^{h} / a\right) .
\end{aligned}
$$

The above imply that $k$ is a function of $v$ and $a$ to be denoted as $k(v, a)$ and such that

$$
k_{v}=-\Delta, \quad k_{a}=(\lambda / a)\left(1-\sigma^{h}\right) k^{m}
$$

Now we use the market clearing conditions for housing and capital markets (29), (30) at steady state to derive the excess demand for housing wealth and the excess supply of saving (over investment)

$$
\begin{aligned}
G^{d}(b, v, a) & \equiv\left(q^{h} \phi^{h}(\pi, r) / \pi\right)(w+((r-\zeta) /(1+r)) b)-(1+\zeta) v \\
G^{s}(b, v, a) & \equiv\left(1-\phi^{y}\right) w+\left(1-\phi^{y}((r-\zeta) /(1+r))\right) b-(1+\zeta)(k+v)
\end{aligned}
$$

so that the reduced form equilibrium steady state conditions for any given $a$ is defined by

$$
\begin{aligned}
& G^{d}(b, v, a)=0 \\
& G^{s}(b, v, a)=0
\end{aligned}
$$

and a PBSS is a positive pair, $\left(b^{*}(a), v^{*}(a)\right)$, such that

$$
0=G^{d}\left(b^{*}(a), v^{*}(a), a\right)=G^{s}\left(b^{*}(a), v^{*}(a), a\right) .
$$

${ }^{\dagger}$ This appendix is intended for publication. An additional online appendix, not for publication, is available on our websites and contains details on the data and further robustness checks. 
Letting $v^{d}(b, a)$ and $v^{s}(b, a)$ be the solutions for $v$ to (A5) and (A6), respectively, for a given pair $(b, a)$, we say that $v^{d}$ is the demand and $v^{s}$ the supply of housing wealth. Intuitively, $v^{d}$ is the households' real expenditure for the stock of available housing and $v^{s}$ defines the amount of housing wealth that is consistent with a capital market equilibrium, i.e., with the available amount of savings, business capital and land value. It turns out that, if $\sigma^{h}=1$ and $\Delta \in(0,1)$, the demand and supply schedules, i.e., $v^{d}(b, a)$ and $v^{s}(b, a)$ in the space $(b, v)$, are well defined, have a unique intersection at $b^{*}(a)$, where $v^{s}$ is steeper than $v^{d}\left(i . e ., v_{b}^{s}>v_{b}^{d}\right)$. This follows also from a key property of our model, i.e., the fact that a rise in bequests has a greater impact on households' saving than on their expenditure on housing (cf. equation (24)).

Now we show that, if $\sigma^{h}=1$ and $\Delta \in(0,1)$, the solutions $v^{d}(b, a)$ and $v^{s}(b, a)$ to (A5) and (A6), if they exist, are unique and such that $v_{b}^{s}>v_{b}^{d}$. In fact, by differentiation of equations (A3), (A4), it follows that, when $\sigma^{h}=1$,

$$
G_{v}^{d}=-1, \quad G_{v}^{s}=-(1-\Delta)
$$

and, hence, by the stated assumptions,

$$
-G_{v}^{d}=1>-G_{v}^{s}>0
$$

Then,

$$
\frac{\partial v^{d}}{\partial b}=\frac{(r-\zeta) \phi^{h}}{(1+\zeta)(r+\delta)}, \quad \frac{\partial v^{s}}{\partial b}=\frac{(1+r)-(r-\zeta) \phi^{y}}{(1+\zeta)(1+r)(1-\Delta)} .
$$

Then, since $1-\Delta \in(0,1)$, a sufficient condition for $v_{b}^{s}>v_{b}^{d}$ is

$$
(r-\zeta)\left((1+r) \phi^{h}+(r+\delta) \phi^{y}\right) \leq(r+\delta)(1+r)
$$

which is clearly verified for all $\phi^{y}$ and $\phi^{h}$ such that $\phi^{y}+\phi^{h} \leq 1$.

Denoting the elasticity of a variable $x$ with respect to $a$ at equilibrium as $\hat{x}_{a}^{*}$, we can compute now the impact of a change in $a$ on the equilibrium values of bequests and housing wealth, as

$$
\hat{b}_{a}^{*}=\frac{\hat{v}_{a}^{d}-\hat{v}_{a}^{s}}{\hat{v}_{b}^{s}-\hat{v}_{b}^{d}}, \quad \hat{v}_{a}^{*}=\hat{v}_{a}^{d}+\hat{v}_{b}^{d} \hat{b}_{a}^{*}
$$

where, for $j=d, s$,

$$
\hat{v}_{a}^{j}=-\frac{a G_{a}^{j}}{v G_{v}^{j}}, \quad \hat{v}_{b}^{j}=-\frac{a G_{b}^{j}}{v G_{v}^{j}}
$$


Since we have shown that $\Delta<1$ implies $\hat{v}_{b}^{s}>\hat{v}_{b}^{d}$, we derive that

$$
\hat{b}_{a}^{*} \geq 0 \quad \Leftrightarrow \quad \hat{v}_{a}^{d} \geq \hat{v}_{a}^{s}
$$

By taking derivatives, we get

$$
\begin{aligned}
& \hat{v}_{a}^{d}=(1-\gamma)\left(1-\mathcal{S}_{k}^{h}\right)\left(1-\phi^{h}\right), \\
& \hat{v}_{a}^{s}=\frac{1}{1-\Delta}\left[(1-\gamma)\left(1-\mathcal{S}_{k}^{h}\right)\left(\frac{\delta+r}{1+r}\right) \phi^{y}+a\left(\frac{\delta+\zeta}{1+r}\right) \mathcal{S}_{k}^{h} \frac{k^{m}}{k^{h}}\left(1-\sigma^{h}\right)\right] .
\end{aligned}
$$

Then, a sufficient condition for $\hat{b}_{a}^{*} \geq 0$ is $\gamma \leq 1, \sigma^{h} \geq 1$ and

$$
0 \leq \Delta \leq 1-\left(\frac{\delta+r}{1+r}\right) \frac{\phi^{y}}{\phi^{y}+\phi^{o}} .
$$

Since

$$
\hat{v}_{a}^{*}=\hat{v}_{a}+\hat{v}_{b} \times \hat{b}_{a}^{*}, \quad \hat{v}_{a} \geq 0, \quad \hat{v}_{b} \geq 0,
$$

the above inequalities guarantee $\hat{v}_{a}^{*} \geq 0$ and $\hat{b}_{a}^{*}=0$ if $\gamma=1$ and $\sigma^{h}=1$. Now, assume $\sigma^{h}=1$. Then using (34), (35), (36), we derive

$$
\begin{aligned}
& \hat{k}_{a}^{*}=-\left(\Delta / \beta^{k}\right) \beta^{h} \hat{v}_{a}^{*} \\
& \hat{y}_{a}^{*}=-\left((1+r) \Delta-(\delta+\zeta) \mathcal{S}_{z}^{h}\right) \beta^{h} \hat{v}_{a}^{*}, \\
& \hat{\beta}_{a}^{*}=((1-\Delta) / \beta)+\left((1+r) \Delta-(\delta+\zeta) \mathcal{S}_{z}^{h}\right) \beta^{h} \hat{v}_{a}^{*}, \\
& \hat{\lambda}_{a}^{*}=\hat{v}_{a}^{*} .
\end{aligned}
$$

\section{A.II Upper Bound on $\Delta$ with Zero Bequests}

Proposition 2. Assume that $b=0$. Then, $\Delta<1$ at equilibrium.

Proof. If $b^{r}=0$, aggregate savings cannot be larger than the wage rate, i.e., $s \leq a w$. We are going to show that this is impossible at equilibrium when $\Delta>1$. In fact, since $\Delta=(\delta+\zeta)\left(a k^{m}-k^{h}\right) / q^{h} y^{h}$, we have

$$
1-\Delta=\frac{q^{h} y^{h}-(\delta+\zeta)\left(a k^{m}-k^{h}\right)}{q^{h} y^{h}} .
$$

Now consider the asset market clearing condition (30) at steady state, i.e.,

$$
s /(1+\zeta)=k+v=\lambda k^{h} / a+(1-\lambda) k^{m}+v .
$$


Since $v=\lambda q^{h} y^{h} / a(\delta+\zeta)$, the above can be written as

$$
\frac{\lambda}{a}\left(q^{h} y^{h}-(\delta+\zeta)\left(a k^{m}-k^{h}\right)\right)=\frac{\delta+\zeta}{1+\zeta}\left(s-(1+\zeta) k^{m}\right),
$$

or, in light of (A9),

$$
\frac{\lambda}{a}(1-\Delta) q^{h} y^{h}=\left(\frac{\delta+n}{1+n}\right)\left(s-(1+\zeta) k^{m}\right) .
$$

Now let $1-\Delta<0$. Then, $\lambda \in[0,1]$ if and only if $s<(1+\zeta) a k^{m}$ and

$$
s>\left(\frac{1+\zeta}{\delta+\zeta}\right)\left(\frac{q^{h} y^{h}+(\delta+\zeta) k^{h}}{a}\right)>w .
$$

Since zero bequests imply $s \leq w$, the above cannot hold in equilibrium. 